\title{
TÜRK BOYLARININ HALK EDEBIYYATINDAN ÖRNEKLER: BESARABYA GAGAUZLARININ AĞIZLARI
}

Mustafa CENGIZZ

Özet

İki bölümden oluşan bu tanıtma ve değerlendirme yazısında, ilk olarak Radloff'un başlattı̆̆ı, Türk Boylarının Halk Edebiyatından Örnekler adlı Proben serisinin X. cildini meydana getiren Besarabya Gagauzlarının Ağızları adlı kitap tanıtılacaktır. İkinci bölümde ise SOBIDER (Sosyal Bilimler Dergisi)'in 13. sayısında, 336-353. sayfalar arasında, Serdar Bulut tarafından yazılmış olan, Türk dilinin Güneybatı grubu yazı dillerinden birini teşkil eden Gagauz Türkçesinin Türkiye'de yayımlanan iki sözlügünün tanıtıldığı çalışma üzerinde durulacak ve çeşitli yönleriyle eleştirilecektir.

Anahtar Kelimeler: Gagauzlar, Sözlük, W. Radloff, V. A. Moşkov, Türk Dili.

\section{THE FOLK LITERATURE OF TURKIC TRIBES: THE DIALECTS OF THE BESSARABIAN GAGAUZ}

\begin{abstract}
In this two part review, firstly the Dialects of the Bessarabian Gagauz which, constitutes the 10th volume of the Proben series named The Folk Literature of Turkic Tribes and was initiated by Radloff will be presented. In the second part, Serdar Bulut's article, which was published in SOBIDER, issue 13, pp. 336-353, on the two dictionaries of Gagauz Turkic, which is one of the written langages of the South-eastern Turkic languages, published in Turkey will be discoursed and reviewed from many aspects.
\end{abstract}

Key Words: The Gagauz, Dictionary, W. Radloff, V. A. Moshkov, Turkic.

1. "Wilhelm Radloff (2015). Türk Boylarının Halk Edebiyatından Örnekler (X. Bölüm): Besarabya Gagauzlarının A Ăızları (Haz. Tülay Çulha ve Muvaffak Duranl1), Ankara: TDK Yayınları, 351 s., ISBN 978-97516-3018-6."

Çulha ile Duranlı tarafindan hazırlanan ve TDK tarafindan yayımlanan eseri tanıtmaya geçmeden önce bir hususu belirtmekte fayda var. Bu çalışma, Radloff'un başlattığ Proben serisinin X. cildini oluşturmaktadır ${ }^{1}$ ve

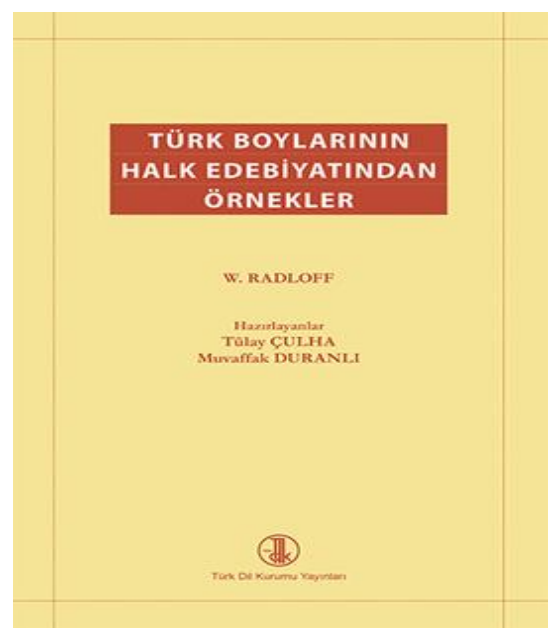

\footnotetext{
* Arş. Gör., Erciyes Üniversitesi, Edebiyat Fakültesi, Çağdaş Türk Lehçeleri ve Edebiyatları Bölümü, KAYSERİ, Elmek: mscengiz2010@gmail.com

${ }^{1}$ V. Moschkoff (1904). Mundarten der bessarabischen Gagausen: Text und Wörterbuch. St. Petersburg: Kaiserliche Akad.der Wiss (Die Sprachen der nördlichen türkischen Stämme, Abt. 1 Proben der Volkslitteratur, 10).
} 
Besarabya Gagauzlarının ağızlarından derlenen metinleri ihtiva etmekte olup ayrıca eserin sonunda Gagauzca Sözlük de bulunmaktadır.

Kitaptaki metinleri derleyen ve sözlüğü hazırlayan kişi, kitabın dış ve iç kapağında yazıldığı gibi Radloff değil, Rus entograf, tarihçi, filolog ve asker Valentin A. Moşkov'dur². Nitekim çalışmanın 1904 yılında Petersburg'da yayımlanan nüshasında, iki ekle birlikte (Mit zwei Beilagen) metni derleyen ve çeviren (gesammelt und übersetzt) kişi olarak Moşkov'un adı geçmektedir (bk. Moşkov, 1904). Fakat Çulha ve Duranlı tarafından hazırlanan bu çalışmada Moşkov'un adı hiç zikredilmemekte, eser tamamen Radloff'a ait gösterilmektedir. Oysa Radloff bu ciltte yalnızca serinin editörü (Herausgegeben von Dr. W. Radloff) olarak kayıtlıdır. Metni hazırlayanların yazmış olduğu ön sözde "Radloff'un 1860-1870 yılları arasında (1864 hariç) yaptığı gezilerde derlediği malzemelerden ibaret olan çalışmalarının 1866-1907 yılları arasını kapsayan ilk yedi cildi bizzat kendisi; sonraki ciltleri başkaları tarafindan derlenmişsir. (s. 9)" şeklinde geçen ifadeler de bu durumu açıkça ortaya koymaktadır. Petersburg yayınında, Moşkov tarafından yazıldığı açıkça belli olan mukaddime bölümünün sonunda imza bulunmamasına rağmen bu yeni yayında Radloff'un adı konulmuştur. Emek ve ortaya konan eser V. A. Moşkov'a aittir. Umarız yeni baskıları yapılırken kapakta Moşkov'un adına yer verilir.

TDK tarafından yayımlanan elimizdeki eser, Radloff yönetiminde Türk Topluluklarının Halk Edebiyatından Örnekler ismiyle yayımlanmış olan serinin X. cildidir (X. Theil) ${ }^{3}$. Kitapta Moşkov tarafından yazılan Rusça mukaddime bölümünün Türkiye Türkçesine çevirisi (s. 2141), metinlerin yazı çevirimi ve Gagauzca-Rusça Sözlük'ün çevirisi yer almaktadır. Ayrıca eserin başında Mehmet Ölmez'e ait bir 'Sunuş' (s.7) yazısı vardır. Kitaptaki çeviri yazılı metinler altı bölüme ayrılmıştır: I. Dinî ve Mitolojik IÇerikli Masal, Hikâye ve Efsaneler' (s. 43151), 'II. Gündelik Yaşamdan Anekdotlar' (s. 153-194), 'III. Bilmeceler' (s. 195-198), 'IV. Atasözleri ve Deyimler' (s.199-205), 'V. Yanıltmaç' (s. 207), 'VI. Şarkılar' (s. 209-247). Çeviri yazılı metinlerden sonra ise 'Ek I Notalar' (s. 249-273) başlığı altında kitapta yer alan türkülerin notalarına yer verilmiştir. Kitabın sonunda ise "Ek II: Besarabya Gagauzlarının Sözlüğü / Gagauzca Sözlük" (s. 275-350) ve "Kaynaklar" (s. 351) bulunmaktadır.

Metin derlemelerinin "Dinî ve Mitolojik Iç̧erikli Masal, Hikâye ve Efsaneler" adlı ilk bölümde 12 varyantla beraber 117 (toplam 129); "Gündelik Yaşamdan Anekdotlar" adlı ikinci bölümde ise 6 varyantla beraber 68 (toplam 74) metin bulunmaktadır. Dolayısıla metinlerin varyantına yeni numara verilmemiş, metnin numarasına ek alfabetik olarak gösterilmiştir. Örneğin 75. metnin varyantı "75a" olarak verilmiş̦tir (s. 121-122). Kitapta ilk iki bölümde toplam 185 metin yer almaktadır. "Bilmeceler" başlığını taşıyan üçüncü bölümde toplamda 98 adet bilmece (s. 195-198); “Atasözleri ve Deyimler" isimli dördüncü bölümde 271 adet atasözü ve deyim (s. 199-205); "Yanıltmaç" başlıklı beşinci bölümde 7 adet yanıltmaç (s. 207); "Şarkılar" adlı altıncı bölümde şarkıların konularına göre başlıklar verilmek suretiyle, 2 varyantla beraber 52 (toplam 54) adet şarkı (s. 209-233) ve yine bu bölümde 1 varyantla beraber 111 (toplamda 112) adet mani (s. 234-247) metni bulunmaktadır.

Çulha ve Duranlı metinlerin çeviri yazısını yaparken orijinal metnin sayfa numaralarını köşeli parantezle belirtmişlerdir. Bu arada çalışmada, Petersburg baskısının 274. sayfası sehven 318 şeklinde numaralandırılmıştır.

\footnotetext{
${ }^{2}$ Moşkov'un çalışmaları için bk. Eren 1998: 228.

${ }^{3}$ Kitabın 1904 yılındaki yayını daha önce Özkan'ın Gagauz sözlükleriyle ilgili bir yazısı içerisinde tanıtılmıştır (2001: 750).
} 
Çalışmanın uzun mukaddime bölümünde Moşkov, sözlük kısmını ilk olarak Gagauz masallarının anlaşılmasına kolaylık sağlayacağı fikriyle oluşturmayı düşündüguünü, fakat sonradan bu kararından vazgeçip Gagauz Türkçesinde seyrek olarak kullanılan kelimeleri de not etmek suretiyle meydana getirdiğini belirtir (s. 37). Metinlerde geçen kelimelerin iki veya daha fazla şekilde görülmesi konusunda ise Moşkov şu bilgileri nakleder: "Burada verilen masallarda okuyucu aynı masalda aynı kelimenin ya avşam ya da ahşam, ya der ya diyer ya da deyör şeklinde yazıldığını görecektir. Bu yüzden ben okuyucuyu, diğer halklarda olduğu gibi, bu ikiliğin masalın kaydedildiği yere ve masalın kaydedildiği kişiye bağlı olarak telaffuzda belirdiği konusunda uyarmalıyım. Gagauzların söyleyişindeki fark sadece bazı kolonilere göre değil, aynı zamanda bu koloninin bölgesine göre de gözlemlenmektedir. Sonuç olarak bazen yaşlılar ve genç kuşak arasında farklılıklar olmaktadır. Burada 'yaşlılar böyle söylerler' ifadesi diğer yerlerden daha sık duyulmaktadır." (s. 38). Moşkov bu bölümde Gagauz ağızlarında görülen fonetik farkl11ıklar konusunda kısmi bilgiler de verir (s. 38-40).

Kitabın sonunda yer verilen, yaklaşık 3000 kelimelik bir söz varlı̆̆ını ihtiva eden sözlük kısmı ilk Gagauz Türkçesi sözlüğü olması bakımından tarihî bir değere sahiptir. Moşkov tarafından derlenerek yayımlanan bu metinler de Gagauz lehçesiyle yazıya geçirilen ilk metinler olma özelliği taşımaktadır.

Çalışmanın sonunda yer alan Sözlük'te madde başları alfabetik sırayla verilmiştir. Orijinal metinde fiillerin yanına (v) konulurken TDK baskısında fiillerden sonra çizgi (-) işareti kullanılmıştır: aban-, abandır-, abandırt- vb. (s. 277). Telaffuzda uzun olan ünlüler yazı çeviriminde gösterilmiş, kelimelerin türevleri ayrı bir madde başı olarak verilmeyip kök veya taban şeklindeki madde başının içerisinde verilmiştir. Birden fazla anlamı bulunan kelimeler ise numaralandırılmıştır. Örnek:

dōru doğru; dōruluk doğruluk; dōrul- doğrulmak, düzelmek; dōrut- yöneltmek; dos dōru dosdoğru, ip gibi doğru (s. 295).

Farklı köklerden gelen, fakat benzer seslik özelliklere sahip olan (sesteş) kelimeler, ayrı madde başlarında gösterilmiştir:

at (1) ad.

at (2) at; atlı atlı; atlı git- atla gitmek (s. 280).

at-(3) atmak, ateş etmek; kendini at- atılmak; atla- ${ }^{4}$ atlamak, atılmak; atmacä kuşu atmaca; attır- attırmak, tohum atmak (cinsel ilişkide); attırık meni, insan dölü; atıl- atılmak; atılayrak dört nala (at yürüyüşü); atılan-atılanın atılarak; atım barut hakkı (s. 280)”.

Sözlükte bir madde başıyla ilgili söz grupları ve cümlelerin de aynı madde içerisinde verildiği görülmektedir:

ārt arka, geri; ārdına ne için (nereye? sorusu); ārdında ne için (nerede? sorusu); ārdına düş- takip etmek; ārdından ardından (nereden? sorusunun devamı); ārdından gitbirinin arkasından gitmek; ārta kaldı bu yev evi boş bırakmak (küfür) (s. 279).

maya 1) şirden; 2) süt gelmezden önce kadının göğsünden çıkan ilk sıvı (s. 320).

mısır 1) Mısır; 2) numda melagris (hindi türünde bir kuş) (s. 320).

\footnotetext{
${ }^{4}$ Orijinal metinde Moşkov atla- fiilini at- madde başı içerisinde vermiştir (1904: 9). Bu fiilin, ayrı bir madde baş1 olarak yer alması gerekirdi.
} 
Yukarıda verilen örnek maddelerde görüldüğü üzere, Çulha ve Duranlı yayınında şeklen Moşkov'un çalışmasının orijinaline sadık kalındığı görülmektedir.

карт - старый; карт кары - старуха; карт кыз - старая дева.

картал - орелъ (Moşkov, 1904: 53).

Gagauz Türkçesiyle ilgili ilk yayın olma özelliğiyle tarihî bir değere sahip olan bu çalışmanın metin ve sözlük kısmı takdir edilesi bir emeğin ürünüdür. O dönemde, Gagauzların yaşadığı yerleri gezerek metinler derlemek ve böyle bir sözlük hazırlamak Türkoloji, özellikle Oğuzcanın söz varlığı için önemli bir hizmettir. Kitaptaki çeviri yazılı metinler, Gagauz Türkçesiyle ilgili çalışma yapmak isteyen araştırmacılara çok değerli malzeme sunmaktadır. Çulha ve Duranlı, Moşkov'un derleyip yayına hazırladığı metinleri Kiril alfabesinden Latin alfabesine aktarıp sözlüğü Rusçadan tercüme ederek Türkiye'deki araştırmacıların istifadesine sunmuş ve önemli bir hizmette bulunmuşlardır.

\section{Gagauz Türkçesinin Sözlükleriyle İlgili Tanıtım Yazısı Üzerine Eleştiriler}

Bulut'un çalışmasının başlığından, mezkûr yazının Gagauz Türkçesi sözlüklerinden Türkiye'de yayımlanmış olanları geniş ölçüde tanıtma amacı taşıdığı anlaşılmaktadır. Araştırmacı yazısında, Türk lehçelerinin geçmişten günümüze kadar olan seyrini kısaca anlattıktan sonra, 'dil' ve 'lehçe' adlandırmalarına da değinmiştir. Yazının başlığı ile ilgisini kuramadığımız bu bölümde yazar, Türk dünyasında dil birliğinin olmadığı, Türkiye ile diğer Türk toplulukları arasında ortak bir yazı dilinin bulunmadığı gibi sorunlara değinmiştir. Bir sözlük tanıtma yazısı olan bu çalışma, "Bir tanıtma yazısında böyle bilgilerin yer alması gerekir mi, yoksa bu tarz bilgiler başka bir araştırmanın konusu mudur, bu bilgiler yazının amacına uygun mudur?" sorularını akla getirmektedir.

Yazarın, çalışmasının adını '...Türkiye'de Yayımlanan Sözlüklerin...' koymasına rağmen, Moşkov tarafından Besarabya Gagauzlarının ağızlarından yapılan derleme metinlerin sözlüğünü çalışmasına dâhil etmediği görülmektedir. Çalışmanın başlığ -özet bölümünde de ifade edildiği üzere- '...Türkiye'de Yayımlanan İki Sözlüğün...' şeklinde olmalı idi.

Bulut yazısında (s. 340) “Günümüzde nüfusu 350.000'i aşan bu Türk kolu, Türk dili ve folklorunu bugün bile kendi aralarında büyük bir bağll1ıkla korumaktadırlar. Evlerinde Türkçe konuşan bu millet, İncil'i Türkçe okumakta, kiliselerinde Türkçe ibadet etmekte ve Türkçe dua etmektedir (Yavuz, 2010: 179)." şeklinde yaptığı alıntıdan sonra sözlerini "Bu sebeplerle bu halkın Müslüman mı yoksa tamamen Hristiyan mı olduğu net olmadığı için benimsenmeleri de zor olmaktadır." yorumu ile devam ettirmektedir. Araştırmacının yazısının bir yerinde de belirttiği üzere Gagauzların büyük çoğunluğu, Hristiyanlığın Ortodoks ${ }^{5}$ mezhebine mensuptur.

\footnotetext{
${ }^{5}$ Balkanlara Türk varlığı 'kuzey’ ve 'güney’ olmak üzere iki koldan gelmiştir. Karadeniz'in kuzeyinden gelen Türk topluluklarının başını Hunlar çekerken, bunları Avar, Bulgar, Peçenek, Oğuz ve Kıpçak unsurları takip etmiştir. Güneyden ise Selçuklu Türkleri ve Osmanlılar Balkanlara gelmiştir. Kuzeyden gelen Türklerin ortak inanışları Tengri, Tanrı, Tanra, Tenri şeklinde olan ve buna nispetle Gök Tanrı Dini olarak adlandırılan inanç sistemi idi. Fakat Türkler burada bu inanç sistemini geliştirememiş ve Bizanslılar tarafindan Hristiyanlaştırılmak istenmişlerdir. Mamafih 10. yüzyılda Balkanlarda, Mani dini ile bağlantılı olduğu düşünülen 'Bogomilizm' adlı yeni bir dinî hareket gelişti. Peçenekler Balkanlara geldiğinde, bu dinî hareket Balkan köylüleri arasında resmî Hristiyan kiliseleri tarafindan 'Apokrif' olarak nitelenen Âdem ve Havva adlı kitaplar başta olmak üzere, çeşitli kitaplarla yayılmış ve taraftar bulabilmiştir. Balkanlara gelen Oğuz ve Kıpçak unsurlar, Bizanslıların telkin ve gayretleriyle Hristiyan olurken, 1266'da Sarı Saltuk önderliğinde Anadolu'dan Balkanlara gelen Türkmenlerin bir kısmı da, Yazıcıŏglu'nun
} 
$\mathrm{Bu}$ cümleden aynı zamanda Ortodoks mezhebine mensup olmayan Gagauz Türklerinin varlığ 1 da anlaşılmalıdır. Fakat bu oran, Ortodoks olanlara kıyasla daha düşük olduğu için birçok kaynakta zikredilmemektedir. Gagauz Türklerinin cenet (cennet), cendem (cehennem), hac, hac1/hacıka, oruç, haram, helal, Allah ${ }^{6}$ vb. gibi İslami terimleri kullanması, ibadetlerini Türkçe olarak yapmaları (Güngör ve Argunşah, 2002: 78) vb. çeşitli uygulamalar araştırmacıyı bazı Gagauz Türklerinin Müslüman olabileceği düşüncesine itmiş olabilir. Bununla birlikte evlilik yoluyla veya çeşitli sebeplerle meydana gelen küçük göçler neticesinde gittikleri Müslüman ülkelerde İslamiyeti kabul eden Gagauzların mevcut olması muhtemeldir. Fakat bunların sayısı çok az olmalıdır ki, kaynaklar Gagauz nüfusunun inancını zikrederken Müslüman olduklarından bahsetmez'. Dolayısıyla Gagauz Türklerinin 'Müslüman m1 yoksa Hristiyan mı oldukları', kaynaklara göre net olarak bellidir; Gagauzlar Hristiyanlığın çeşitli mezheplerine mensup bir Türk topluluğudur. Ayrıca Gagauzların Moldova ve Ukrayna gibi toplu olarak bulundukları ülkelerde yaşadıkları zorluklar, inançlarıyla ilgili değil, nüfuslarının az olmasından kaynaklanmaktadır. Şöyle ki, Gagauz Yeri ve Ukrayna'dan başka Romanya, Özbekistan, Kazakistan, Bulgaristan, Yunanistan, Brezilya vb. yerlerde yaşayan Gagauz nüfusu, genel nüfusa oranla oldukça düşük olduğu için çoklukla genel nüfus içerisinde değerlendirilmiştir. Söz gelimi Bulgaristan'da Bulgar, Yunanistan'da Yunan, Romanya'da Romen, Moldova'da Moldovan olarak addedilmişlerdir ${ }^{8}$. Hâl böyle olunca başka ülkelerde yaşayan Gagauz kimliğinin öne çıkması ve benimsenmeleri kolay olmamaktadır.

Yazının başlığı ile muhtevası arasında ilişki kuramadığımız başka bir nokta da alt başlıklardır. Çalışmanın başlı̆̆ından anlaşıldığına göre yazı, Türkiye'de yayımlanan Gagauz Türkçesi sözlüklerini tanıtmayı amaçlamaktadır. Amaç böyle olduğu hâlde 'Gagavuzlar', 'Gagavuz Adı', 'Gagavuz Türkçesi' gibi alt başlıkların bulunması ve bu alt başlıkların içerisinde Gagauz ağızlarından bahsedilerek bunların fonetik özelliklerine değinilmesinin amaca uygun olmadığı kanaatindeyiz (bk. Bulut, 2017: 342-343).

Makalede dikkati çeken eksikliklerden bir tanesi de Gagauz Türklerinin Türkiye'de tanınmasında önemli rol oynayan araştırmacıların zikredilmesinde görülmektedir. Yaşar Nabi Nayır, Hamdullah Suphi Tanrı̈ver ve Nevzat Özkan gibi araştırmacılar zikredilirken, Türkiye'de Gagauzların dilleri ve kültürleri üzerine önemli kitap ve makaleleri olan Harun

bildirdiğine göre, 'Sarı Saltuk öldükten sonra mürted ve ahriyan oldular.'. 11. Yüzyıla değin Hristiyan kiliseler arasında herhangi bir dinî veya mezhebî ayrım olmamasına rağmen, 11. Yüzyılın ikinci yarısında Hristiyan kiliseleri Ortodoks ve Katolik şeklinde, mezhebî olarak ayrışmaya başladı. O dönemde Dobruca bölgesinde bulunan Gagauzlar da Ortodoks Bizans kilisesinin etkisi altında olduğundan dolayı Ortodoks olmuşlardır. Bu sebeple Gagauzların büyük çoğunluğu Ortodoks, yani Pravoslav mezhebine mensup olup Moskova Patrikliğine bağlıdır. Bununla birlikte günümüzde de Gagauzlar arasında Babtist, Evangelist ve Adventist Protestan gruplar bulunmaktadır (Güngör ve Argunşah, 2002: 75-77).

${ }^{6}$ Gagauzların kullanmış oldukları bu terimler, İslamiyet ile alakalı olmayıp, Hristiyan ilahiyatındaki manalarıyla kullanılagelmektedir (bk. Güngör, 2016: 235; ayrıca bk. Çakir, 2011).

${ }^{7}$ De Pauly, bir kısım Gagauz Türkünün, çıkarları doğrultusunda, herhangi bir sayı belirtmeksizin, Müslümanlığı kabul ettiğini zikretse (1862: 110) de bu kaynaktan başka Müslüman Gagauzların mevcudiyetine dair bir malumat elde edilememiştir.

${ }^{8}$ Özellikle belirtmek gerekir ki, birçok yabancı ulus, Gagauzların Türk olduğunu kabul etmemiş ve onları temsil etme hakkının kendilerinde olduğunu ortaya koymak için çeşitli faraziyeler ortaya atmışlardır. Bu uğurda özellikle Bulgaristan ve Yunanistan'ın çabalarını hatırlatmak gerekir. Öyle ki, Yunanistan'ın, Ortodoks terminolojiden başka Gagauzlarla hiçbir ortak yanı bulunmadığı hâlde, filolojik olarak 'Gagauz' adını Gagavüs olarak telaffuz etmeleri sebebiyle bu telaffuzdaki 'Gaga' sözcüğünün bir Arnavut soyadı olduğunu, 'Vus' sözcüğünün ise Yunancada 'İnek' anlamına geldiğini öne sürerek Gagauzlar üzerinde nüfuz kazanmaya çalıştı̆̆ bilinmektedir (Moşkov, 2006: 34-35; ayrica bk. Kapaló, 2011: 62; Ciachir 1998: 12-13). 
Güngör, Mustafa Argunşah ve İsmail Ulutaş gibi araştırmacılar zikredilmediği gibi, bu araştırmacıların yayınlarına da bakılmadığı görülmektedir.

Makalenin kaynakçasında da bazı yanlışlıklar göze çarpmaktadır. 'Gagavuz Adı' (s. 341) alt başlı̆ğında verilen bilgilerin bir kısmı, Türk Lehçeleri Grameri'nin 'Gagavuz Türkçesi' bölümünden alıntılanmış olduğu hâlde referans olarak editörün ismi gösterilmiş ve kaynaklar kısmına bu şekilde kaydedilmiştir. Oysa Türk Lehçeleri Grameri'nde her bir lehçeyi alanında uzman kişiler yazmıştır. Kaynakçada bölümün yazarı olarak bu kimselerin ismi yazılmalıdır. Araştırmacının istifade ettiği ve yazarın adını zikretmeden editörün ismini yazdığı 'Gagavuz Türkçesi’ bölümü Nevzat Özkan tarafından yazılmıştır (bk. Özkan, 2007: 81-170). Araştırmacının metin içinde ve kaynaklarda verdiği bibliyografya bilgisinin, okuyucu/araştırıcı üzerinde, ilgili kısmın Ahmet B. Ercilasun tarafından yazıldığı şeklinde yanlış bir algıya sebep olma ihtimali yüksektir. Dolayısıyla kaynaklar kısmında bu çalışma, şu şekilde olmalıydı:

Özkan, Nevzat (2007). "Gagavuz Türkçesi”, Türk Lehçeleri Grameri (Ed. Ahmet B. Ercilasun), Ankara: Akçağ Yayınları, s. 81-170.

Araştırmacı çalışmasında İsmail Kaynak ve Abdülmecit Doğru tarafindan Türkiye Türkçesine çevrilen ve Kültür Bakanlığı yayınları arasından çıkan Gagauz Türkçesinin Sözlüğü adlı çalışmanın içeriğiyle ilgili bilgiler verirken "Gagavuz Türkçesinin Sözlüğü isimli çalışma, Gagavuz Türkçesinin bugünkü ilk sözlük denemesi olma özelliği göstermektedir. Bu sözlük Türkiye Türkçesine aktarılan ilk Gagavuz Türkçesi sözlüğü olması hususuyla da önemlidir.” demektedir9 (s. 346). Bu çalışmanın 1973 yılında basılan özgün yayımında madde başı açıklamaları Rusçadır ${ }^{10}$. Yukarıda tanıtılan eserde de görüldüğü üzere, Moşkov'un Proben serisinin X. cildinde yer alan Gagauzskiy Slovar' (114 s.) adlı sözlüğü ise 1904 yllında basılmıştır. Dolayısıyla Gagauz Türkçesinin ilk sözlüğ̈ Moşkov’un hazırladığı çalışmadır. Bulut'un tanıttığı Gagauz Türkçesinin Sözlügü̈'nün başındaki 'Müelliflerin Önsözü’ kısmında da Gagauz Türkçesinin ilk sözlüğünün XX. yüzyılın başında, Moşkov’un malzemesine ek olarak derlenen üç bin kelimelik sözlük olduğu kaydedilmiştir (Kaynak ve Doğru 1991: IX). Yine aynı sözlüğün içeriğiyle ilgili bilgiler verilirken "Madde başları açıklanırken, açıklama kısmı geniş tutulmuş ve kelimelerin tam olarak anlanabilmesi sağlanmıştır." şeklinde bir cümleye yer vermiştir (s. 347). Bu bilginin, sadece çok anlamlı bir kısım sözcüklerle temel fiil ve isimler için geçerli olduğunu belirtelim. Sözlükte birçok madde başı olduğu gibi aktarılmış, bazı sözcüklerin farklı anlamları belirtilmemiştir. Özkan'ın da tespit ettiği gibi 'arabacı, başka, becerikli, benek, benekli, bilgisiz' gibi bir kısım madde başlarına ise hiçbir açıklama yapılmamış ve 'aynı anlamda' şeklinde not düşülmüştür (2001: 753). Bunlara ek olarak bazı maddelerin açıklama kısımlarında başka madde başlarına gönderme yapıldığı hâlde, gönderme yapılan madde başı, sözlükte bulunmamaktadır. 'buulu, cumerka, enden, fronton, günnaall, güneeli, mühür vb. bu tarz kelimelere örnektir. Ayrıca sözlükte K harfinin madde başı sıralamasında da hata olduğunu belirtmek gerekir (Özkan, 2001: 753). Araştırmacının bu çalışmayı tanıtırken eksik ve kusurlu yönlerini de belirtmesi daha faydalı olurdu.

\footnotetext{
9 Benzer bilgi yanlışı, çalışmanın sonuç kısmında da "Bu çalışmamızda Gagavuz Türkçesiyle ilgili Türkiye'de yayımlanan iki önemli sözlük üzerinde durulmuştur. Bu sözlüklerden birisi Gagavuz Türkçesinin yazılan ilk sözlüğünün Türkiye Türkçesine aktarılmış şekli iken... " şeklinde tekrarlanmıştır (s. 351).

${ }^{10}$ Gaydarci, G. A. - Koltsa E, K. - Pokrovskaya L. A. - Tukan B. P., Redaktör: N. A. Baskakov., GagauzskogoRussko-Moldavskiy Slovar', Moskva, 1973.
} 
Çalışmanın sonuç kısmında "İncelediğimiz bu iki eserin de en önemli eksiklerinden biri hiç şüphesiz Gagavuz Türkçesine has olan "ä" ve "ê" ünlüleriyle ilgili kelimelerin sözlükte gösterilmemiş olmasıdır. Herhalde yazarlar burada bir karışıklık olmasın ve Türkiye Türkleri kelimeleri daha doğru anlasın diye bu harflerle ilgili kelimeleri "e" harfiyle karşılamışlardır. Aslında ilgili harflerin karşıladıkları sesler verilmek koşuluyla bu harflerle ilgili kelimelere sözlükte yer verilebilirdi. Gagavuz Türkçesiyle ilgili Türkiye'de yapılacak diğer sözlük çalışmalarında bu konuya dikkat edilmesi önemlidir." şeklinde bir değerlendirme yapılmaktadır (s.352). Oysa tanıtılan çalışmalardan Özkan'ın gramerinin sözlük kısmına baktığımızda cümlä 'cümle, hepsi, tamam(1)', ferecä 'kadın giysisi' (s. 234), güllä 'top mermisi, gülle', günää 'günah', günäh 'günah', günehkär 'günahkâr' (s. 236), haylicä 'pek çok, epeyce' (s. 237), kaarä 'başka, başkası' (s. 239), kelemä 'kelime, söz' (s. 240), kukumäy 'baykuş' (s. 243), laalä 'lâle' (s. 244), paskellä 'paskalya' (s. 249) vb. birçok örnekte ä sesinin yer aldığı görülmektedir ${ }^{11}$. Özkan, çalışmasının sözlük kısmını hazırlarken ê sesinin gösterimi için á işaretini kullanmış ve bu sesi barındıran kelimeleri de sözlüğüne almıştır. Özkan'ın verdiği bilgiye göre bu ses, a 1 arası bir ses olan ve Türkiye Türkçesinde karşılığı bulunmayan bir ünlüdür. Bu ünlü, Mihail Çakır'ın Romen harfleriyle yayımladığı metinlerde âe (1e) harfleriyle belirtilmiştir (Özkan 1996: 42-43). Gagauz Türkçesinde daha sonra ê sesiyle karşılanmıştır. Özkan'ın tanıtılan bu çalışması incelenirken "á ünlüsü" (s. 42-43) başlıklı bölüme dikkat edilseydi, herhâlde bu özellik bir eksiklik olarak görülmeyecekti. Ayrıca Özkan'ın çalışmasının 'Sözlük' kısmını tanıtan bir araştırmacının, Güngör ve Argunşah tarafından hazırlanan Gagauz Türkleri: Tarih-Dil-Folklor ve Halk Edebiyatı adlı çalışmada yer alan metinlerin 'Sözlük' kısmını da tanıtması beklenirdi.

\section{Sonuç}

Yurt dışında Türk dili ve edebiyatı ile ilgili birçok kıymetli yayın bulunmaktadır ve bu yayınların bazılarına, özellikle Rusya'da yayımlanan kaynaklara ulaşmak kolay olmamaktadır. $\mathrm{Bu}$ yayınların bir kısmı metin neşri hâlinde iken, bir kısmı da dil incelemesi şeklindedir. $\mathrm{Bu}$ kıymetli eserlerden bazılarının, en azından metin neşirlerinin, çeviri yazısı ve tercümeleri yapılarak Türkiye Türkolojisine kazandırılması son derece önemlidir. Çulha ve Duranlı tarafından çeviri yazımı ve Türkiye Türkçesine tercümesi yapılan Moşkov'un bu eseri, sadece Gagauz Türklerinin halk edebiyatı ile ilgili muhtevaya sahip olmakla kalmamakta, aynı zamanda 20. yüzyılın başlarında Gagauz Türklerinin diliyle ilgili de önemli malzeme barındırmaktadır. Moşkov'un metinleri yayımlamasının üzerinden bir asırdan fazla zaman geçti. $\mathrm{Bu}$ çalışmadan hareketle, çağdaş Gagauzcanın söz varlığ ile 20. yüzyılın başlarında kullanılmış olan Gagauzca kelimeler gramatik ve semantik bakımdan mukayese edilebilir ve meydana gelen değişiklikler ortaya konulabilir.

TDK yayınları arasından çıkan bu kıymetli çalışmanın kapağına 'Besarabya Gagauzlarının Ağızları' ibaresi de eklenmelidir. İç kapakta bulunan bu ibareyle Proben serisinin $X$. cildi olduğunu belirten benzer bilgilerin dış kapağa da konulması kitabın doğru tanınmasını sağladığı gibi ilgiyi de arttırabilir.

Bilimsel yazılarda eksik bilgi vermek, yanlış bilgi vermekten yeğdir. Bu sebeple bir kitap hakkında hüküm vermeden önce bu hükmü bilimsel olarak teyit etmek gerekir. Gagauz Türkçesinin Sözlüğü adlı çalışmayı ilk Gagauz sözlüğü olarak nitelendirmek, Moşkov’un

11 Örnekleri krş. Çebotar ve Dron 2002. 
hazırladığı çalışmayı ve onun emeğini görmezden gelmek demek olur. Tanıtılan bir eseri dikkatle incelemek de son derece önemlidir. Kitabın içerisinde var olup tanıtıcının dikkatinden kaçan noktaların olması doğal karşılanabilir. Lakin bu durumdan kaynaklanan olumsuz eleştiriler kitabın kusuru olarak değil, tanıtıcının gözünden kaçan noktalar olarak görülür ve yükümlülük tanıtıcıya aittir.

Tanıtma ve değerlendirme yazılarında olabildiğince nesnel olunmalıdır. Tanıtılan kitabın olumlu yönlerinin ortaya konulması yanında eksiklerinin ve kusurlarının da belirtilmesi gerekir. Bulut'un tanıttığı sözlük, çeşitli kusurları olmakla birlikte sınırlı bir söz varlığını ihtiva etmektedir. Gagauz Türkçesinin en kapsamlı sözlügü ise P. Çebotar ve İ. Dron tarafından Kişinev'de yayımlanan Gagauzça-Rusça-Romınca Sözlük (Гагаузско-Русско-Румынский Словарь) adlı çalışmadır (2002).

\section{Kaynakça}

BULUT, S. (2017). "Güney-Batı (Oğuz) Grubu Türk Lehçelerinden Gagavuz Türkçesi Üzerine Türkiye'de Yayınlanan Sözlüklerin Söz Varlığı, İçerik Özellikleri ve Tanıtımı”, Sosyal Bilimler Dergisi (SOBIDERR), Y. 4, S. 13, Ağustos 2017, s. 336-353.

ÇAKİR, M. (2011). "Gagauzların Allaha İnanması İçin”, Sabaa Yıldızı: Etnik BilimiKultura-Tarih, S.51/2011, s. 12-13.

ÇAKİR, M. (1998). Basarabyalı Gagauzların Tarihi (Basarabielâ Gagauzlarân İstorieasâ), Haz. Harun Güngör, Niğde: Tolunay Yayıncılık.

ÇEBOTAR, P. ve DRON İ. (2002). Gagauzça-Rusça-Romınca Sözlük (ГагаузскоРусско-Румынский Словарь), Chişinău: Pontos.

DE PAULY, T. (1862). Description Ethnographique Les Peuples De La Russie, SaintPetersbourg.

EREN, H. (1998). Türklük Bilimi Sözlüğ̈̈: I. Yabancı Türkologlar, Ankara: TDK Yayınları.

GÜNGÖR, H. ve ARGUNŞAH M. (2002). Gagauz Türkleri: Tarih-Dil-Folklor ve Halk Edebiyatı, Ankara: Kültür Bakanlığı Yayınları.

GÜNGÖR, H. (2016). "Gagauzların Hıristiyanlığı Kabulü ve İnanışlarındaki İslamî Unsurlar Meselesi”, Türk Bodun Bilimi Araştırmaları, İstanbul: Bilge Kültür Sanat Yay., s. 232237.

KAPAlÓ, J. A. (2011). Text, Context and Performance: Gagauz Folk Religion in Discourse and Practice, Leiden: Brill.

KAYNAK, İ. ve DOĞRU, A. (Aktaranlar), (1991). Gagauz Türkçesinin Sözlüğü, Ankara: Kültür Bakanlı̆̆g Yayınları.

MOŞKOV, V. A. (1904). Mundarten der bessarabischen Gagausen: Text und Wörterbuch. St. Peterburg: Kaiserliche Akad. der Wiss (Die Sprachen der nördlichen türkischen Stämme, Abt. 1 Proben der Volkslitteratur, 10).

MOŞKOV, V. A. (2006). Balkan Yarımadasında Türk Kavimleri (Çev. Elena İvanova), Elazığ: Manas Yayıncılık. 
ÖZKAN, N. (2001). “Gagavuz Türkçesinin Sözlükleri Üzerine” Türk Dünyası Dil ve Edebiyat Dergisi, Güz/2, s. 749-760.

ÖZKAN, N. (2007). “Gagavuz Türkçesi”, Türk Lehçeleri Grameri (Ed. Ahmet B. Ercilasun), Ankara: Akçağ Yayınları.

RADLOFF, W. (2015). Türk Boylarının Halk Edebiyatından Örnekler: Besarabya Gagauzlarının A ̌̆ızları (Haz. Tülay Çulha ve Muvaffak Duranlı), Ankara: TDK Yayınları.

\section{Kisaltmalar}

bk. : Bakını.

krş. : : Karşıslaştırınız. 